\title{
Implementação e difusão do programa Seis Sigma no Brasil
}

\author{
Marly Monteiro de Carvalho \\ LINDA LeE Ho \\ Silvia Helena Boarin Pinto \\ USP
}

\begin{abstract}
Resumo
Os objetivos deste trabalho são identificar o grau de difusão, os principais aspectos da implantação e os resultados obtidos com a adoção do programa Seis Sigma em empresas brasileiras de grande porte. A abordagem metodológica adotada foi um levantamento do tipo survey, cujas informações foram coletadas através de um questionário estruturado preenchido por 198 profissionais da área de qualidade de diferentes empresas de grande porte. Os resultados sugerem que mesmo em empresas de grande porte a difusão do Seis Sigma ainda não é expressiva [23,5\%]. As empresas que implementaram este programa já possuíam em sua maioria outros programas de qualidade adotados e relataram ter obtido ganhos financeiros superiores ao montante investido na implementação do Seis Sigma, bem com ganhos de qualidade e de produtividade. Além disso, as empresas relataram existir sinergia entre a implementação do Seis Sigma e de outras abordagens de gestão da qualidade.
\end{abstract}

Palavras-chave

Programas de qualidade, programa Seis Sigma, gestão da qualidade.

\section{Six Sigma program implementation and diffusion in Brazil}

\begin{abstract}
The objectives of this paper are to identify the degree of diffusion, the main aspects of the Six Sigma program implementation and its results in the largest Brazilian companies. The research methodology approach was a survey, data were gathered from a structured questionnaire answered by 198 professionals responsible for the quality area in largest Brazilian companies from different sectors. The results pointed out that even in the largest companies; the diffusion of the Six Sigma quality program is not expressive [23.5\%]. In most of the companies that have implemented such quality program had yet other quality programs implemented. Financial profits and quality and productivity improvement were results reported by the respondents. Moreover, the companies highlight the synergy of the Six Sigma program and other quality management approaches.
\end{abstract}

Key words

Quality programs, Six Sigma program, quality management. 


\section{INTRODUĈ̣̃O}

Anunciado por alguns autores como o programa de qualidade do século XXI, o programa Seis Sigma surgiu na década de 1980, na Motorola, e se difundiu em empresas de grande porte como General Electric, Allied Signal e Citibank (MITCHELL, 1992; HARRY, 1998; HARRY; SCHRODER, 2000; PANDE et al., 2001; BASU, 2004). No Brasil, este programa foi trazido pelas subsidiárias destas organizações (BOARIN PINTO et al., 2006).

Segundo Carvalho (2002) a difusão do programa Seis Sigma deu-se no bojo das cifras expressivas dos ganhos divulgados por estas empresas, além de outros benefícios relatados como a redução dos custos, o aumento no valor das ações, o acréscimo no número de clientes e na retenção, entre outros. No entanto, o autor destaca que esses resultados baseiam-se em relatos de casos de sucesso, havendo uma lacuna de estudos empíricos que evidenciassem esses ganhos.

Além disto, diversos autores alertam para o fato de que diversas empresas não compreendem corretamente o significado do programa Seis Sigma, o que prejudica sua difusão nas organizações (CONNOR, 2003, COOPER; NOORMAN, 2003, OLEXA, 2003, PHILLIPS, 2002, WATSON, 2003, WELCH, 2003a e 2003b). Conseqüentemente, a lacuna entre teoria e prática relacionada ao programa Seis Sigma é uma questão relevante para as comunidades acadêmica e empresarial (LINDERMAN et al., 2003; ANTONY, 2004; BOARIN PINTO et al, 2006).

Neste contexto, o presente artigo pretende discutir a implementação e a difusão do programa Seis Sigma em empresas de grande porte brasileiras, a partir de uma abordagem metodológica quantitativa. O tema é relevante no cenário atual, em que as organizações investem quantias significativas em diversos programas de melhoria da qualidade e da produtividade, que são implementados simultaneamente nas organizações, sem que haja uma preocupação de entender os aspectos sinérgicos entre eles.

$\mathrm{O}$ artigo está estruturado em cinco seções. A segunda e terceira seções apresentam a discussão teórica e a abordagem metodológica proposta para a pesquisa de campo, respectivamente. A quarta seção traz os resultados da pesquisa de campo e sua discussão. Finalmente, a última seção traz as conclusões e recomendações para trabalhos futuros.

\section{PROGRAMA SEIS SIGMA: SÍNTESE DA DISCUSSÃO TEÓRICA}

O programa Seis Sigma foi criado na Motorola com o objetivo de auxiliar a resolução de seus problemas de qualidade, mas com um forte apelo na obtenção de resultados, pois a empresa já havia implantado diversos programas de qualidade e obtivera poucos resultados positivos. Em 1998, com a divulgação de ganhos financeiros, acima de 1,3 bilhão de dólares, pela Motorola, atribuídos ao programa Seis Sigma, esta abordagem inicialmente se difundiu pelas empresas americanas, e posteriormente, através de suas subsidiária difundiu-se globalmente (MITCHELL, 1992; HARRY, 1998; HARRY; SCHRODER, 2000).

Diversos autores definem o programa Seis Sigma como uma estratégia gerencial muito disciplinada e quantitativa tendo como objetivo o aumento significativo da lucratividade das organizações, através da melhoria da qualidade, do aumento da satisfação dos clientes e dos consumidores (BASU, 2004; BLAKESLEE, 2001; SNEE; HOERL, 2002; INGLE; ROE, 2001; PANDE et al., 2001; SNEE, 2004).

Para Anabri (2002), a metodologia Seis Sigma pode ser entendida através da expressão: Seis Sigma $=$ TQM + GFC $+\mathrm{DFQ}+\mathrm{RF}+\mathrm{AP}$, em que TQM representa Total Quality Management; GFC é o grande foco do programa nos clientes; DFQ indica a análise dos dados realizada com o auxílio das consagradas ferramentas da qualidade; RF mostra os resultados financeiros dos projetos; e AP é a administração através de projetos Seis Sigma.

Como a implementação de programas de qualidade nas organizações data do século passado, Carvalho e Rotondaro (2006) alertam para o fato de que é difícil estabelecer as fronteiras do programa Seis Sigma com as outras abordagens de Gestão da Qualidade, marcando como aspectos distintivos o forte alinhamento estratégico do portfolio de projetos Seis Sigma, a abordagem orientada a projetos, a adoção do pensamento estatístico sistematizado em um roteiro prescritivo e o uso de um indicador único, que é o índice de capacidade sigma, que serve para benchmarking e para a aferição dos ganhos dos projetos Seis Sigma. Lloréns-Montes e Molina (2006) destacam como os três elementos distintivos principais do programa Seis Sigma: ofoco estratégico, pensamento estatístico e metodologia sistematizada.

Além disso, McAdam e Lafferty (2004) advertem que o grau de abrangência que as organizações denominam de programa Seis Sigma varia significativamente, em especial naquelas que adotam simultaneamente outros programas. Contudo os autores relatam que a adequada adoção do programa Seis Sigma traz uma significativa mudança cultural na organização, em relação aos seus problemas e também quanto à forma de identificá-los e tratá-los (MCADAM; EVANS, 2004).

Neste contexto, apesar de duas décadas de implementação dos programas Seis Sigma, os principais construtos ainda não têm as fronteiras bem definidas com os demais programas de qualidade, conforme será discutido nas subseções subseqüentes desta revisão da literatura.

\section{Programa Seis Sigma: conceito e definições}

Partindo-se dos principais aspectos distintivos do programa Seis Sigma destacados anteriormente, busca-se discutir 
os principais conceitos e definições de programa Seis Sigma disponíveis na literatura.

O foco estratégico pode ser evidenciado na forma de mensuração direta dos benefícios do programa, no apoio da alta administração da empresa e no alinhamento do portfolio de projetos Seis Sigma às estratégias organizacionais.

Diferentemente das demais abordagens que advogavam sobre os custos da qualidade e no trade-off entre prevenção e avaliação (JURAN, 1962; CAMPANELLA, 1999), a abordagem Seis Sigma fala de ganhos da qualidade, calculados com base nos resultados dos projetos Seis Sigma. Esta avaliação é realizada geralmente por setores de contabilidade, com base em técnicas de avaliação econômica de projetos tais como análise do valor presente (ROTONDARO, 2002). DeFeo (2000) também destaca que os projetos Seis Sigma estão orientados para conseguir o retorno sobre o investimento (ROI).

A visão estratégica do programa Seis Sigma é destacada por diversos autores (HARRY, 1998; CARVALHO, 2002; CONNOR, 2003; WATSON, 2003; ROBERTS, 2004; SNEE, 2004; CARVALHO; ROTONDARO, 2006). Para Harry (1998) o programa Seis Sigma é uma estratégia que podem levar a ganhos substanciais em lucratividade e qualidade.

Outro aspecto distintivo é a abordagem de gestão da qualidade por projetos, com forte alinhamento do portfolio de projetos às estratégias de negócio (CARVALHO, 2002; CARVALHO; ROTONDARO, 2006). Segundo Sehwail e De Yong (2003) o programa Seis Sigma identifica e alinha os projetos com objetivos estratégicos e metas do negócio. Carvalho (2002) corrobora esta visão atribuindo à seleção dos projetos um papel crucial nos programas Seis Sigma. O processo de seleção deve assegurar a alocação ideal dos recursos em projetos prioritários, alinhados à estratégia da empresa, com impacto não só na melhoria da eficiência, mas também da eficácia da empresa. Para isto, Carvalho, 2002, sustenta que devem ser promovidos processos estruturados de obtenção da voz do consumidor e da voz do processo.

A terceira característica distintiva, a metodologia sistematizada do programa Seis Sigma é composta pelos métodos Design for Six Sigma (DFSS) e o Define, Measure, Analyze, Improve and Control (DMAIC). O DFSS é empregado no desenvolvimento de novos produtos (bens ou serviços) e processos, sendo estruturado da seguinte forma: Define - definir, Measure - medir, Analyze - analisar, Design - planejar e Verify - verificar (DMADV). O DMAIC é utilizado para a melhoria de produtos e serviços existentes, sendo estruturado para atingir as metas de capacidade do programa Seis Sigma através de cinco fases: Define - definir, Measure medir, Analyze - analisar, Improve - melhorar e Control - controlar (DMAIC). Esse método é também chamado de "Modelo para Melhoria de Performance" e é o mais difundido nas empresas. Na fase definir são identificados os clientes e suas necessidades; na fase medir os processos são mensurados e as performances analisadas; na fase analisar são verificadas as causas dos principais defeitos; na fase melhorar são analisadas as formas para eliminar as causas dos defeitos; e na fase controlar é verificado se as melhorias implementadas estão sob controle de forma a manter os benefícios alcançados (BREYFOGLE, 1999).

O programa Seis Sigma utiliza como indicador de desempenho o índice de capacidade, que tem como meta atingir

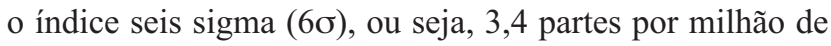
defeituosos, admitindo-se um deslocamento da média do processo em relação ao valor nominal em 1,5 desvios-padrão (sigma). A obtenção desta meta classificaria a organização como "classe mundial", dado que diversos autores enunciam que a maioria das empresas possui seus produtos e serviços operando entre 3 e 4 sigmas (ROTONDARO, 2002; ELLIOTT, 2003; OLEXA, 2003; ROBERTS, 2004).

\section{Fatores-chave na implementação do programa Seis Sigma}

A literatura sobre o programa Seis Sigma está repleta de casos de sucesso em empresas classe mundial, dentre elas a Motorola, a General Electric e a Allied Signal (BLAKESLEE, 2001; ECKES, 2001; PANDE et al., 2001, SNEE; HOERL, 2002; INGLE; ROE, 2001).

Antony e Banuelas (2002) fizeram um dos primeiros estudos empíricos, com abordagem quantitativa do tipo survey, sobre o programa Seis Sigma, tendo como base as empresas de manufatura e de serviços de grande porte localizadas no Reino Unido. Das 45 companhias que responderam ao questionário, 37\% (16 companhias) estavam aplicando o programa Seis Sigma. O questionário proposto continha 11 fatores-chave para o sucesso na implementação deste programa, dos quais o fator considerado de maior importância para a implantação do programa Seis Sigma foi o "envolvimento e o comprometimento da alta administração com o programa", conforme também observado nos trabalhos de Kwak e Anbari (2004), Starbird (2002) e Johnson e Swisher (2003), embora sem a mesma base empírica.

Antony e Banuelas (2002) também destacaram outros fatores, que obtiveram prioridade acima da média: "habilidades de gerenciamento de projeto", "priorização e seleção de projeto, revisões e tracking" e "foco no cliente". Por outro lado, os autores também destacaram três fatores que apresentaram importância inferior à média, quais sejam: "alinhamento à estratégia de negócio", "treinamento e entendimento da metodologia Seis Sigma", e "ferramentas e técnicas".

Embora no estudo de Antony e Banuelas (2002) o treinamento não apareça entre os fatores mais importantes no emprego do programa Seis Sigma, em estudos de casos de diversos outros autores, a formação da equipe que conduzirá o programa Seis Sigma é destacada como um elemento 
importante para o sucesso deste programa (BLAKESLEE, 2001; HOERL; SNEE, 2002; PANDE et al., 2001; SNEE, 2004, INGLE; ROE, 2001; JOHNSON; SWISHER, 2003; KWAK; ANBARI, 2004; CARVALHO; ROTONDARO, 2006). Os papéis da equipe do programa Seis Sigma têm alguns de seus títulos baseados nas artes marciais, tais como faixa-preta (Black Belts) e faixa-verde (Green Belts), segundo sua expertise nas ferramentas e técnicas do programa Seis Sigma e sua dedicação aos projetos (CARVALHO; ROTONDARO, 2006). Além desses profissionais é designado um executivo, denominado líder, como responsável pela implantação do programa Seis Sigma, que é apoiado pelos Campeões, ou seja, executivos (diretores e gerentes) que desdobram o programa Seis Sigma em toda a organização.

Um dos fatores que estabelecem o sucesso do programa Seis Sigma, segundo Aguiar (2002), é a sua estrutura de implantação, que deve ser conduzida da seguinte forma: uma metodologia de solução de problemas e de desenvolvimento de novos produtos ou serviços (DMAIC e o DFSS); uma estrutura de responsabilidade e funções para o programa; uma vigorosa estrutura de treinamentos; e uma política adequada de pessoal para sensibilizar os colaboradores para a mudança de cultura. Antony e Banuelas (2004) identificaram que as ferramentas da qualidade mais adotadas no programa

Seis Sigma são: diagrama de causa e efeito, gráficos de controle e de pareto, análise de regressão, desdobramento da função qualidade - quality function deployment (QFD), teste de hipótese, análise de modo e efeito da falha (FMEA).

Outros autores enfatizam a seleção e condução dos projetos como primordiais para o sucesso do programa Seis Sigma, pois os projetos cuidadosamente escolhidos obterão resultados rápidos e significativos para a organização e, por conseguinte, auxiliarão o sucesso do programa (CARVALHO, 2002; LYNCH et al., 2003; KWAK; ANBARI, 2004). Johnson e Swisher (2003) alertam para a importância da seleção cuidadosa de líderes de projeto por suas habilidades da liderança e para a escolha e seleção estratégica de projetos. Já Starbird (2002) destaca aspectos relacionados ao gerenciamento dos projetos Seis Sigma como um fator-chave, destacando o acompanhamento do desempenho dos projetos através de relatórios de status de atividade de projetos e consumo de recursos, bem como dos resultados dos projetos terminados. Starbird (2002) aponta ainda para a necessidade de integração dos projetos Seis Sigma.

A literatura de casos de sucessos do programa Seis Sigma relata casos em grandes empresas, com predominância de organizações manufatureiras (BLAKESLEE, 2001, ECKES, 2001, PANDE et al., 2001, SNEE; HOERL, 2002, INGLE;ROE, 2001, BOARIN PINTO et al, 2006). No setor de serviços, também foram verificados casos de adoção programa no setor de serviços, entre eles o setor de saúde, como é o caso do hospital da cruz vermelha Holandesa, que obteve benefícios financeiros significativos, conforme relatado por Heuvel et al. (2005), da ordem de 1,2 milhões de euros, sendo que a perspectiva para o próximo ano é estimada em 3 milhões de euros, conforme o estudo.

Antony (2004) fez um levantamento em 23 empresas de serviços do Reino Unido, a maioria das de grande porte $(80 \%)$. Nas empresas que possuem Seis Sigma o programa tinha sido implementado a menos de três anos com o objetivo principal de reduzir e controlar custos. Dentro os fatores-chave no sucesso da implementação do programa, foram considerados mais importantes os seguintes: ligar o programa Seis Sigma às estratégias de negócios; ter foco no cliente; habilidades para gerenciar projetos; comprometimento da liderança executiva e alta administração;infra-estrutura organizacional; seleção e priorização de projetos;

\section{os 198 questionários válidos, apenas 46 zações responderam que tinham implementado o programa Seis Sigma ( 23\%).}

Embora predominem os relatos de casos de sucesso do programa Seis Sigma, também alguns casos de insucesso foram observados na literatura. Os principais fatores para o fracasso deste programa são: a fraca liderança exercida pelos gestores responsáveis pela execução do programa; a incorreta definição dos objetivos e metas a serem alcançados; a fraca gestão dos projetos; a escassez dos diversos tipos de recursos para a implantação e manutenção do programa; e a formação inadequada nas técnicas estatísticas e administrativas do programa (WELCH, 2003a e b). Segundo Senapati (2004), vale lembrar que John Akers prometeu mudar a IBM com o programa Seis Sigma, mas a tentativa foi abandonada rapidamente quando ele deixou de ser CEO (chief executive officer) em 1993.

\section{Programa Seis Sigma e outras abordagens de Gestão da Qualidade}

O programa Seis Sigma representa em vários aspectos uma implementação disciplinada dos princípios, de ferramentas e técnicas de controle e gerenciamento da qualidade, também utilizada por outros programas de qualidade, que empregam o "pensamento estatístico" para reduzir a variabilidade dos processos e buscar a melhoria contínua.

Conforme já advogava Deming, deve-se reduzir a variação dos processos com a utilização de técnicas estatísticas, 
portanto, o "pensar estatisticamente" foi empregado com sucesso nas décadas anteriores (WOLEK, 2004). Dale et al. (2000) enfatizam ainda que o programa Seis Sigma tem como base antigos conceitos da engenharia da qualidade, que buscavam entender e eliminar as causas de variação e projetar a manufatura. Além disto, vários autores destacam a semelhança do DMAIC com o ciclo PDCA (plan, do, check e act), elaborado por Shewhart na década de 20, para argumentam ainda que outros modelos de gerenciamento da qualidade, assim como o programa Seis Sigma, buscam dimentos, as ferramentas e métodos, buscando uma visão sistêmica. orientar as ações de melhoria contínua. Pfeifer et al. (2004) relacionar a estratégia, a estrutura organizacional, os proce-

grama Seis Sigma o Ciclo de Deming, TQM e Engenharia da Qualidade a partir de oito atributos, conforme ilustra o Quadro 2.

Shankar (2003) também sustenta que as diversas abordagens da qualidade, como os critérios das premiações de qualidade (Malcolm Baldrige, Prêmio Nacional da Qualidade ou Deming), o programa Seis Sigma e as normas ISO 9001:2000, não são independentes umas das outras, ou seja, elas podem e devem coexistir harmoniosamente, não havendo a necessidade de abandono de uma sistemática para implantação da outra. Embora o autor sugira que o ideal seria a adoção das normas ISO 9001:2000 e, posteriormente, do programa Seis Sigma. Adicionalmente, o autor argumenta que os prêmios da qualidade oferecem a integração, o programa Seis Sigma controla as melhorias e a norma ISO 9001:2000 focaliza o básico. Outros autores têm explorado a convergência do programa Seis Sigma e do Gerenciamento Enxuto (Lean Management) (ARNHEITER; MALEYEFF, 2005). Não obstante, o autor reconhece que poucas empresas possuem recursos para a implantação de diversos programas concomitantemente.

Neste contexto, a integração entre o programa Seis Sigma e outros programas de melhoria da qualidade é plausível. Segundo Phillips (2002), o programa Seis Sigma pode auxiliar na implantação das normas ISO 9001:2000, pois é uma ferramenta bastante eficaz, transformando um sistema de gestão da qualidade, que por vezes é implantado apenas por imposição da direção ou do mercado, em algo valorizado pela organização e acatado como um mecanismo de melhoria contínua do desempenho e de gestão eficaz dos processos. Por outro lado, a implantação das normas ISO 9001:2000 pode auxiliar a empresa que pretende aplicar o programa Seis Sigma, fornecendo a base inicial, ou seja, preparando a organização para a implementação do programa Seis Sigma que necessita de muito treinamento e certo amadurecimento organizacional. Uma comparação entre as seções e subseções das normas ISO 9001:2000 e o programa Seis Sigma, pode ser vista no Quadro 1.

De Mast (2004) faz uma análise comparativa do programa Seis Sigma com o método de Taguchi e o sistema Shainin, baseado em uma estrutura teórica com sete elementos: "redes explicativas e suas estruturas", "tipos de fatores de influência na modelagem dos projetos", "fases dos processos de melhoria", "regras para a definição operacional do problema", "heurísticas para a descoberta de potenciais fatores de influência", "natureza interativa dos projetos de melhoria", e "padrões de melhoria". O autor conclui que o programa Seis Sigma é o mais completo.

Senapati (2004) faz uma análise comparativa entre o pro-
Relações entre os programas de qualidade adotados nas empresas, como por exemplo a ISO 9001:2000, a ISO 14001, o TQM e o programa Seis Sigma, representam um aspecto proeminente para as organizações, pois em várias companhias estes modelos coexistem harmoniosamente e podem apresentar características sinérgicas. Empresas em que os referidos programas são tratados isoladamente dissipam recursos humanos e financeiros, podem causar competição desnecessária entre departamentos e ocasionar descrédito dos colaboradores (HAMMER, 2002; HOERL, 2001; SUN, 2004).

\section{METODOLOGIA}

Dado o contexto teórico apresentado neste artigo, buscou-se contribuir para a pesquisa nesta área elucidando as seguintes questões:

- Grau de difusão dos programas Seis Sigma em empresas de grande porte brasileiras;

- Principais características das empresas de grande porte que adotam o programa Seis Sigma;

- Principais fatores associados a implementação dos programa Seis Sigma;

- Ferramentas estatísticas mais utilizadas;

- Retornos obtidos e o investimento necessário.

A abordagem estatística adotada apresenta características de pesquisa exploratória, com plano de amostragem não 
Quadro 1: Comparação entre as normas ISO 9001:2000 e o programa Seis Sigma.

\begin{tabular}{|c|c|c|}
\hline $\begin{array}{l}\text { ITEM DA NORMA } \\
\text { ISO 9001:2000 }\end{array}$ & $\begin{array}{c}\text { DESCRIÇÃO DO ITEM DA NORMA ISO } \\
\text { 9001:2000 }\end{array}$ & ITENS DO PROGRAMA SEIS SIGMA \\
\hline $\begin{array}{l}\text { Seção } 5.4 \text { - } \\
\text { Responsabilidade } \\
\text { da direção }\end{array}$ & $\begin{array}{l}\text { Exige que a direção da organização estabeleça } \\
\text { objetivos da qualidade para a empresa e } \\
\text { assegure que o planejamento do Sistema de } \\
\text { Gestão da Qualidade (SGQ) esteja de acordo } \\
\text { com os objetivos. }\end{array}$ & $\begin{array}{l}\text { Estabelecer objetivos de DPMO (defeito por } \\
\text { milhão de oportunidades). }\end{array}$ \\
\hline $\begin{array}{l}\text { Seção } 8.4 \text { - } \\
\text { Medição, Análise e } \\
\text { Melhoria }\end{array}$ & $\begin{array}{l}\text { Exige que a empresa identifique, reúna e } \\
\text { analise os dados para demonstrar que o } \\
\text { Sistema de Gestão da Qualidade (SGQ) é } \\
\text { adequado. }\end{array}$ & $\begin{array}{l}\text { Os dados coletados servirão para os } \\
\text { projetos Seis Sigma. }\end{array}$ \\
\hline $\begin{array}{l}\text { Seção } 8.5 .1- \\
\text { Melhoria contínua }\end{array}$ & $\begin{array}{l}\text { Exige que a organização melhore } \\
\text { continuamente o seu SGQ (geralmente focaliza } \\
\text { custo ou redução da variabilidade). }\end{array}$ & $\begin{array}{l}\text { A redução de custos ou a diminuição da } \\
\text { variabilidade dos processos internos da } \\
\text { organização são os princípios relevantes do } \\
\text { programa Seis Sigma. }\end{array}$ \\
\hline $\begin{array}{l}\text { Subseção } 4.1 \text { - } \\
\text { Sistema de Gestão } \\
\text { da Qualidade }\end{array}$ & $\begin{array}{l}\text { Exige que a organização implante e mantenha } \\
\text { um SGQ e melhore continuamente sua } \\
\text { eficácia. Deve identificar os processos } \\
\text { necessários para o SGQ e sua aplicação em } \\
\text { toda a organização. }\end{array}$ & $\begin{array}{l}\text { É compatível com a filosofia Seis Sigma, ou } \\
\text { seja, os blacks belts e green belts recebem } \\
\text { grande carga de treinamentos técnicos para } \\
\text { agir dessa maneira, focalizando projetos } \\
\text { específicos em todos os departamentos da } \\
\text { organização. }\end{array}$ \\
\hline $\begin{array}{l}\text { Seção } 5.1 \text { - } \\
\text { Comportamento da } \\
\text { direção }\end{array}$ & $\begin{array}{l}\text { Exige que a direção demonstre seu } \\
\text { comprometimento com a elaboração e } \\
\text { manutenção do SGQ e com a melhoria } \\
\text { contínua de sua eficácia. }\end{array}$ & $\begin{array}{l}\text { Os resultados dos projetos Seis Sigma } \\
\text { podem ser utilizados como entrada para } \\
\text { a análise crítica do SGQ pela direção, } \\
\text { demonstrando seu envolvimento com as } \\
\text { melhorias contínuas do sistema. }\end{array}$ \\
\hline $\begin{array}{l}\text { Seção } 5.2 \text { - } \\
\text { Foco no cliente } \\
\text { e Subseção } \\
\text { 8.2.1 Medição e } \\
\text { Monitoramento } \\
\text { da Satisfação dos } \\
\text { Clientes }\end{array}$ & $\begin{array}{l}\text { Exige que a direção garanta que a empresa } \\
\text { esteja comprometida com os requisitos } \\
\text { dos clientes, garantindo sua satisfação. } \\
\text { A organização deve medir e monitorar as } \\
\text { informações provenientes dos clientes. }\end{array}$ & $\begin{array}{l}\text { A principal pretenção do programa Seis } \\
\text { Sigma é aumentar a satisfação dos clientes, } \\
\text { utilizando para tanto os projetos que } \\
\text { eliminam as Não-Conformidades relacionadas } \\
\text { às características críticas para a qualidade. } \\
\text { O SGQ de uma organização, de acordo com } \\
\text { as normas ISO } 9001: 2000 \text {, deve estar } \\
\text { comprometido com o aumento da satisfação } \\
\text { dos clientes, compatível com o programa } \\
\text { Seis Sigma. }\end{array}$ \\
\hline $\begin{array}{l}\text { Seção } 7.2 .1 \text { - } \\
\text { Processos } \\
\text { relacionados a } \\
\text { Clientes }\end{array}$ & $\begin{array}{l}\text { Exige que a empresa conheça as } \\
\text { determinações dos clientes, os regulamentos } \\
\text { e a realidade do mercado em que atua. }\end{array}$ & $\begin{array}{l}\text { Para verificar as causas das Não- } \\
\text { Conformidades, a filosofia Seis Sigma analisa } \\
\text { criteriosamente o projeto dos produtos e os } \\
\text { processos. }\end{array}$ \\
\hline $\begin{array}{l}\text { Subseçãa 8.2. - } \\
\text { Medições e } \\
\text { Monitoramento } \\
\text { (Auditorias) }\end{array}$ & $\begin{array}{l}\text { Exige que a empresa estabeleça e implante } \\
\text { programas de auditorias internas da } \\
\text { qualidade. }\end{array}$ & $\begin{array}{l}\text { As auditorias internas do SGQ poderiam } \\
\text { verificar a veracidade e a quantificação dos } \\
\text { ganhos dos projetos Seis Sigma. }\end{array}$ \\
\hline $\begin{array}{l}\text { Seção } 8.5 \text { - } \\
\text { Melhorias } \\
\text { (Melhoria Contínua, } \\
\text { Ações Corretivas e } \\
\text { Preventivas) }\end{array}$ & $\begin{array}{l}\text { Exige que a direção demonstre seu } \\
\text { comprometimento com a elaboração e } \\
\text { manutenção do SGQ e com a melhoria } \\
\text { contínua de sua eficácia. }\end{array}$ & $\begin{array}{l}\text { O objetivo dos projetos Seis Sigma é } \\
\text { elaborar Ações Corretivas e Preventivas, } \\
\text { ocasionando melhorias para o SGQ, } \\
\text { devidamente verificadas por técnicas } \\
\text { estatísticas, por pessoal devidamente } \\
\text { treinado. }\end{array}$ \\
\hline
\end{tabular}

Fonte: Adaptado de Pande et al. (2001) e Ricondo e Viles (2004). 
probabilística e, utilizando critério de elegibilidade para selecionar as respostas válidas a partir das informações coletadas (HAIR JR. et al, 2005; BABBIE, 1999). Este estudo também se caracteriza por um corte transversal, tendo como unidade de análise as organizações de grande porte em que atuam os respondentes (HAIR JR. et al., 2005). A população considerada como representativa das empresas de grande porte brasileiras foi a lista das 1.000 (mil) maiores empresas brasileiras, tomando como referência a base de dados do periódico Valor Econômico (2004).

Dada a natureza das questões de pesquisa, optou-se por adotar estratégia de pesquisa quantitativa. Segundo Godoy (1995), em um estudo quantitativo o pesquisador preocupa-se com a medição objetiva e a quantificação dos resultados. De acordo com Bryman (1989), no campo da pesquisa organizacional, este tipo de pesquisa requer que a coleta de dados seja feita por meio de questionários autoaplicáveis, entrevistas estruturadas ou semi-estruturadas. Nesta pesquisa optou-se pelo envio de questionários autoaplicáveis por correio convencional e eletrônico, destinados aos responsáveis pela área de qualidade das organizações. No entanto, antes do envio dos questionários foi feito um pré-teste em duas organizações, o que possibilitou uma revisão do instrumento, que resultou em sua redução, além de serem redigidas novamente questões que geraram dúvidas nos respondentes e incluído um glossário (COOPER; SCHINDLER, 2003).
O questionário utilizado nesta pesquisa era composto por três blocos: caracterização da empresa e do entrevistado; análise da gestão da qualidade na organização; e análise do programa Seis Sigma.

O bloco 2, análise de gestão da qualidade na organização, é composto de 27 questões fechadas, que abordam diversos aspectos, tais como: programas adotados, estrutura e pessoal envolvido com a área de qualidade, motivos de implantação dos programas, valores investidos, dentre outras. O terceiro bloco continha questões específicas sobre o programa Seis Sigma, que enfatizavam aspectos relacionados aos seguintes aspectos: estrutura da equipe de implementação do programa, fatores-chave na implementação, projetos Seis Sigma e apuração dos ganhos.

Os questionários foram tabulados e analisados utilizando o software estatístico Minitab, versão 14.

\section{RESULTADOS DA PESQUISA DE CAMPO}

Foram obtidos 198 questionários válidos ( $20 \%$ do total enviado). Nesta seção é apresentada a caracterização da amostra, bem como os principais resultados da pesquisa de campo.

\section{Caracterização da amostra}

Dos 198 questionários válidos, apenas 46 organizações responderam que tinham implementado o programa Seis Sigma $(\sim 23 \%)$. A seguir passa-se a caracterizar estas empresas.

Quadro 2: Análise Comparativa entre abordagens da Qualidade.

\begin{tabular}{|c|c|c|c|c|}
\hline ATRIBUTO & $\begin{array}{c}\text { PROGRAMA SEIS } \\
\text { SIGMA }\end{array}$ & GIGLO DE DEMING & там & $\begin{array}{l}\text { ENGENHARIA DA } \\
\text { QUALIDADE }\end{array}$ \\
\hline $\begin{array}{l}\text { Abordagem } \\
\text { orientada a processo }\end{array}$ & Forte ênfase & Implícito & Implícito & Forte ênfase \\
\hline Foco no cliente & Implícito & Invisível & Explícito & Implícito \\
\hline $\begin{array}{l}\text { Abordagem } \\
\text { estatística }\end{array}$ & Tem base estatística & $\begin{array}{l}\text { Não está restrita } \\
\text { a abordagem } \\
\text { estatística }\end{array}$ & $\begin{array}{l}\text { Ferramentas têm } \\
\text { base estatística }\end{array}$ & $\begin{array}{l}\text { Uso de ferramenta } \\
\text { estatística }\end{array}$ \\
\hline $\begin{array}{l}\text { Conteúdo } \\
\text { comportamental }\end{array}$ & Existe & Não enfatiza & Enfatiza & Não aborda o tema \\
\hline Facilidade & $\begin{array}{l}\text { Implementação com } \\
\text { base em objetivos }\end{array}$ & $\begin{array}{l}\text { Guia fácil para } \\
\text { solução de } \\
\text { problemas }\end{array}$ & Fácil implementação & Dificuldade moderada \\
\hline Custo & $\begin{array}{l}\text { Alto para médio } \\
\text { [depende do projeto] }\end{array}$ & $\begin{array}{l}\text { Geralmente baixo } \\
\text { (depende do projeto) }\end{array}$ & $\begin{array}{l}\text { Geralmente } \\
\text { moderado }\end{array}$ & $\begin{array}{l}\text { Não tem estimativas } \\
\text { disponíveis }\end{array}$ \\
\hline Duração & Alta & $\begin{array}{l}\text { Extensão do projeto } \\
\text { depende do escopo }\end{array}$ & $\begin{array}{l}\text { Tamanho do projeto é } \\
\text { moderado }\end{array}$ & $\begin{array}{l}\text { Não foi possível } \\
\text { avaliar }\end{array}$ \\
\hline Papel dos executivos & Top-down & Não enfatizado & Top-down & Botton-up \\
\hline
\end{tabular}

Fonte: Adaptado de Senapati, 2004. 
Dentre as 46 empresas que implementaram o programa Seis Sigma, a maioria $(86,7 \%)$ tem faturamento anual superior a cinqüenta milhões de reais e mais de mil colaboradores $(84,8 \%)$. Aproximadamente $73 \%$ da amostra (33 empresas) está localizada no Estado de São Paulo, seguido pelos Estados de Minas Gerais (13\%) e de Santa Catarina (7\%).

Dentre as 46 empresas que implementam o programa Seis Sigma, pode-se verificar a incidência do programa em 24 setores industriais, com maior concentração em manufatura (87\%), sendo apenas três organizações do setor de serviços, dentre elas serviços hospitalares, venda e manutenção de equipamentos médicos e hospitalares e serviços de informação e processamento de dados. Destaca-se que os setores de maior ocorrência foram o "metalomecânico" e "veículos automotores e autopeças", ambos com (15\%), seguidos do setor "químico e petroquímico", conforme ilustra a Figura 1.

É possível observar ainda na Figura 1 que as empresas respondentes dos setores eletroeletrônico e siderúrgico estão empatadas $(6,5 \%)$, seguidas pelas empresas dos setores farmacêutico, telecomunicações e têxtil, com 4,3\%. Para os demais 16 setores houve apenas uma ocorrência.

No que concerne ao tempo de implementação do programa, observou-se uma média de 6,75 anos. No entanto, pode-se observar na Figura 2 que existem duas empresas que implementaram pioneiramente o programa, quase que simultaneamente às suas matrizes no Exterior (1987 e
1990). A maior freqüência de implementação ocorreu em 2003 , dado que em $25 \%$ da amostra o programa iniciou-se há quatro anos.

A principal motivação para a implementação do programa Seis Sigma relatada pela maioria das empresas foi a "melhoria da qualidade e produtividade", apontada com alta concordância por 40 empresas (87\%), seguida pela opção "exigência do cliente" com $63 \%$, "exportação" com $61 \%$, "imposição da matriz" com 56\% e "marketing" com 52\%. No entanto, o grau de importância destas motivações variou, conforme ilustra a Figura 3. A opção que figurou com maior grau de importância e com maior freqüência foi também a "melhoria da qualidade e produtividade", apontada com alta importância por 37 das 40 empresas que assinalaram esta opção. Destaca-se que a opção de "exportação" obteve grau de importância "baixo" pela maioria dos respondentes (64\%) que assinalaram esta opção, o mesmo ocorrendo com "exigência do cliente" e "marketing".

A maioria das empresas (70\%) também relatou que contrataram consultorias externas para auxiliar a implantação do programa Seis Sigma. Destaca-se ainda que 90\% delas relataram que as consultorias foram um fator facilitador no processo de implementação do programa.

Conforme sugere a literatura, a maioria das empresas que adotam o programa Seis Sigma associam-no a outras abordagens de gestão da qualidade, sendo que a maioria adota

Figura 1: Distribuição das empresas por setor.

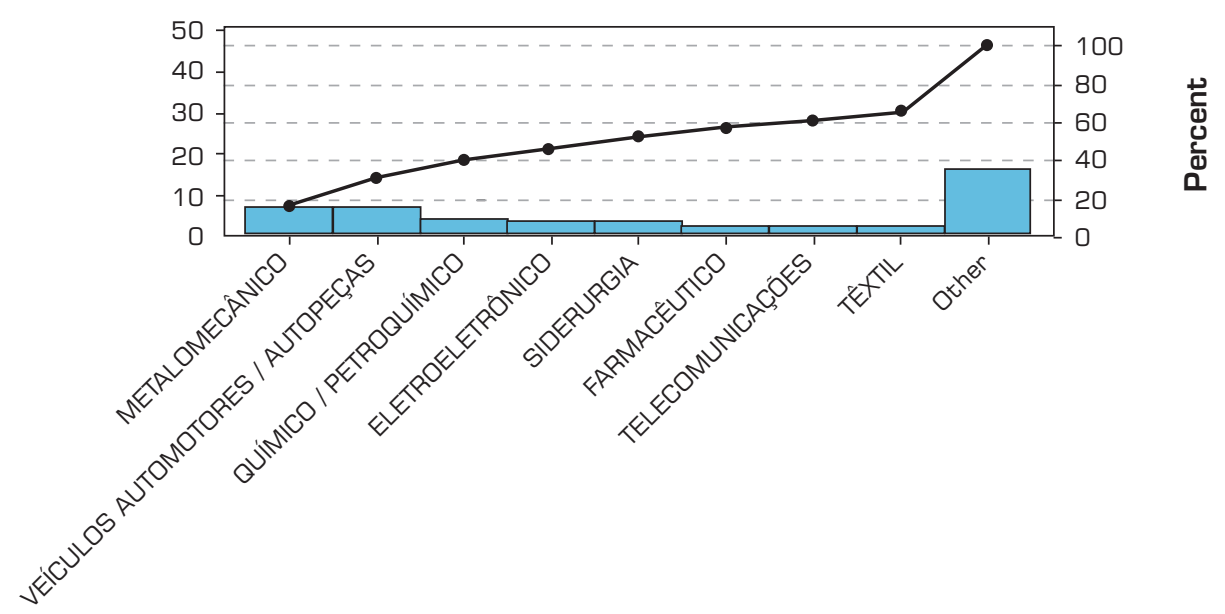

SETOR

$\begin{array}{lrrrrrrrrr}\text { Count } & 7 & 7 & 4 & 3 & 3 & 2 & 2 & 2 & 16 \\ \text { Percent } & 15,2 & 15,2 & 8,7 & 6,5 & 6,5 & 4,3 & 4,3 & 4,3 & 34,8 \\ \text { Cum \% } & 15,2 & 30,4 & 39,1 & 45,7 & 52,2 & 56,5 & 60,9 & 65,2 & 100,0\end{array}$


Figura 2: Distribuição da amostra segundo o tempo de implementação do programa Seis Sigma.

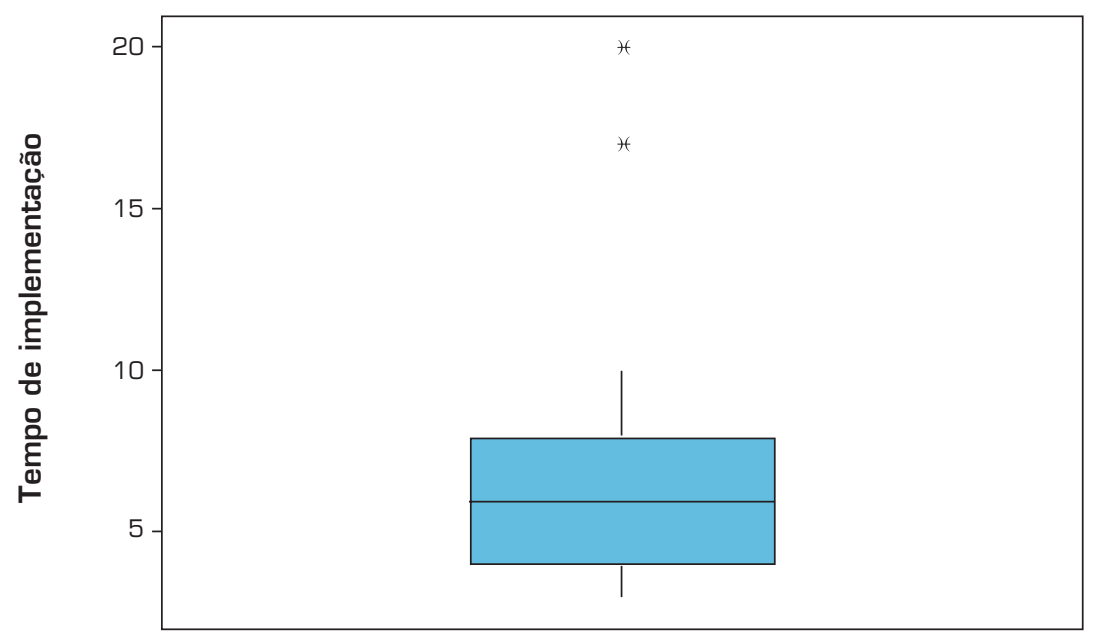

Figura 3: Motivação para implementação do programa Seis Sigma estratificada segundo a importância.

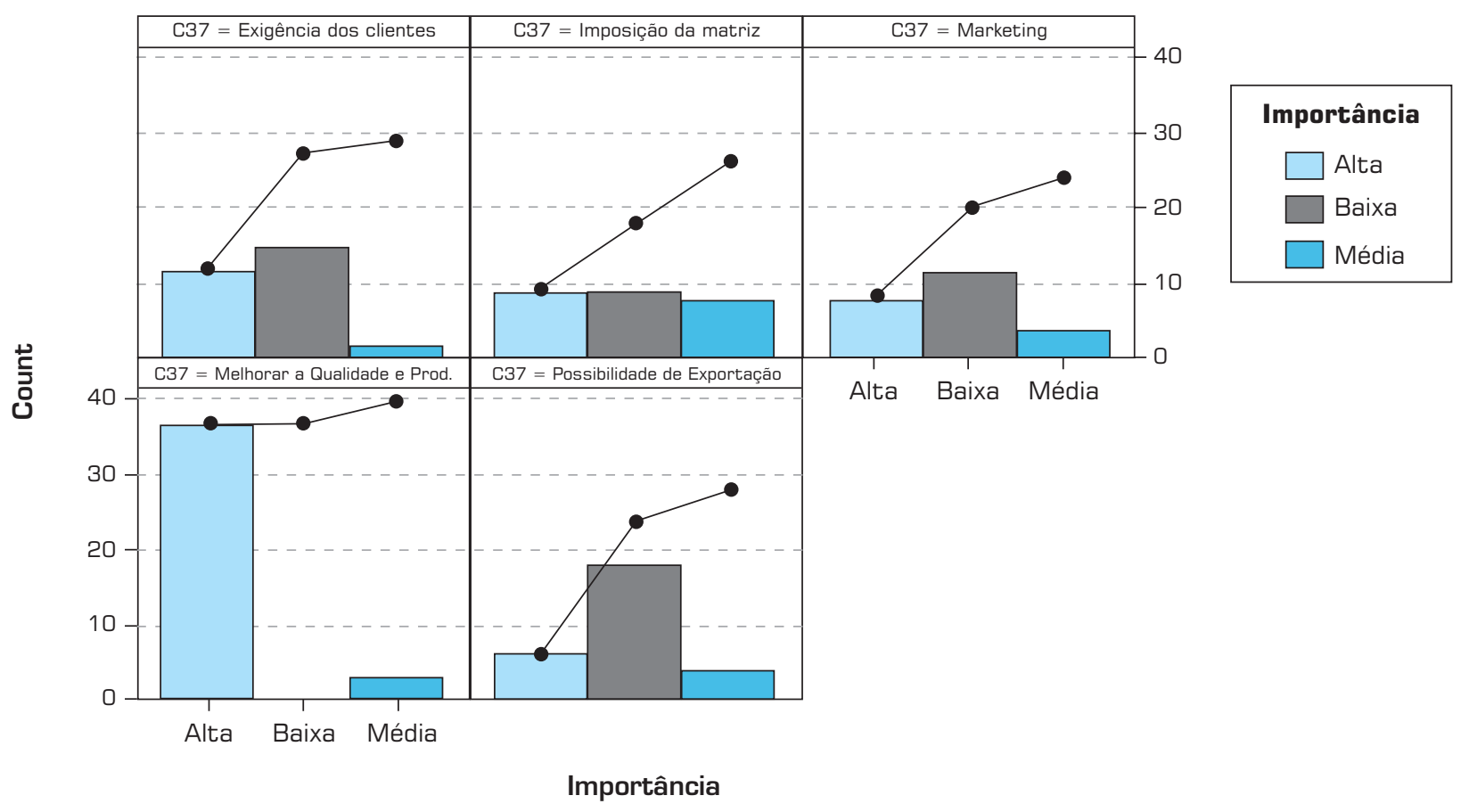


em conjunto as normas ISO 9001:2000 (84,8\%), seguido da associação com as normas ISO $14000(65,2 \%)$ e do TQM $(28,3 \%)$. Apenas três empresas (6,5\%) relataram utilizar somente o programa Seis Sigma. Além disso, 13 empresas (28\%) relataram que adotam o programa Seis Sigma associado a programas corporativos, que mesclam abordagens de melhoria diversas tais como manufatura enxuta (lean productian), boas práticas de fabricação (BPF) e manutenção produtiva total (Total Productive Maintenance - TPM) entre outras.

Destaca-se que a utilização de vários programas concomitantemente é bastante comum, dado que $67,4 \%$ das empresas adotam três ou mais abordagens de qualidade, restringindo-se as abordagens ISO 9000 e 14000 e TQM, sem utilizar a categoria outros, em que aparecem vários programas corporativos e de gestão em geral, conforme já comentado. A associação mais comum $(58,7 \%)$ é das normas de Gestão da Qualidade e Ambiental (ISO 9000 e 14000) ao programa Seis Sigma. Observa-se ainda que $27 \%$ das empresas da amostra se inscreveram para concorrer a premiações de qualidade, das quais 50\% concorreram ao Prêmio Nacional da Qualidade (PNQ) e as demais concorreram a premiações diversas como a do CNI e do SESI.

\section{Programa Seis Sigma: fatores-chave na implementação}

Tomando como base os fatores-chave na implementação do programa Seis Sigma, apresentados na seção teórica deste artigo, observou-se que "o envolvimento e o com- prometimento da alta administração com o programa" foi apontado por 32 respondentes $(69,6 \%)$ como um fator de alta importância, conforme já enfatizava a literatura (ANTONY; BANUELAS, 2002; KWAK; ANBARI, 2004; STARBIRD, 2002, JOHNSON; SWISHER, 2003). Apenas cinco empresas $(10,9 \%)$ apresentaram dificuldades no processo de implementação, devido à falta de apoio da alta administração.

A Figura 4 apresenta a lista dos fatores que facilitaram e dificultaram a implementação do programa Seis Sigma nas organizações estudadas.

Observa-se na Figura 4 que os dois fatores apontados como facilitadores na implementação foram "disponibilidade de recursos financeiros" e "apoio da alta administração", assinalados por $67 \%$ e $65 \%$ dos respondentes, respectivamente. No que concerne ao fator "disponibilidade de recursos financeiros", 56\% dos respondentes que assinalaram esta opção o julgaram um fator de importância "alta", que é inferior a importância atribuída ao fator "apoio da alta administração", que obteve $67 \%$ de importância "alta".

Dentre os fatores que dificultaram a implementação do programa Seis Sigma, destacam-se: a "disponibilidade dos funcionários" e a "complexidade das operações", que foram assinalados por $46 \%$ e $35 \%$ dos respondentes, respectivamente (ver Figura 4). No que concerne ao fator "disponibilidade de recursos financeiros", $56 \%$ dos respondentes que assinalaram esta opção o julgaram um fator de importância "alta", que é inferior à importância atribuída ao fator "apoio da alta administração", que obteve $67 \%$ de importância "alta".

Figura 4: Fatores que facilitaram x dificultaram a implementação do programa Seis Sigma.

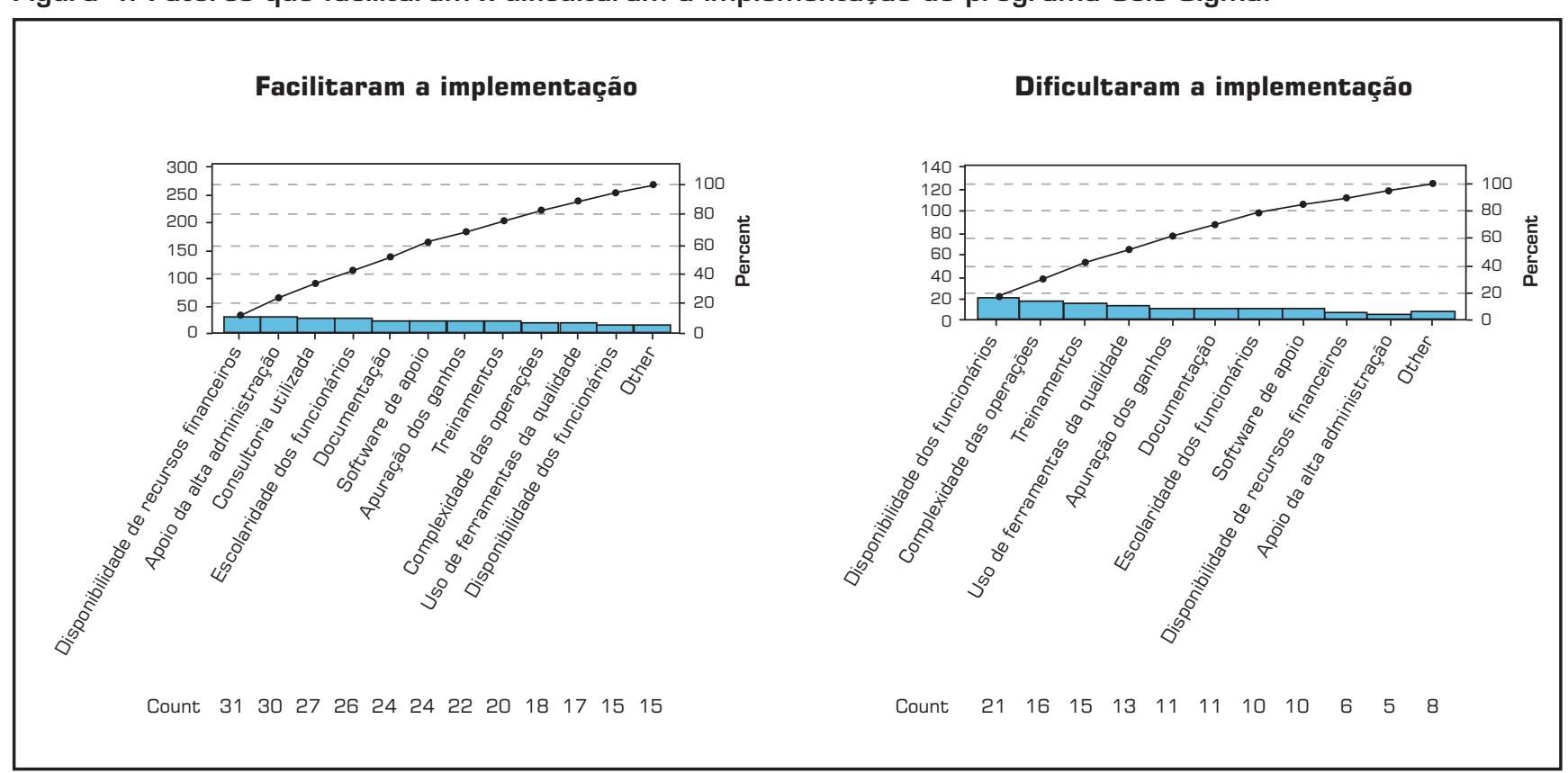


Para o fator "treinamento", assim como na literatura, a amostra ficou dividida, dado que $57 \%$ julgou que o treinamento foi um fator que facilitou o processo de implementação do programa e $43 \%$ relatou que este foi um fator que dificultou o processo de implementação.

Considerando as categorias de belts, observa-se que das 36 empresas que responderam a esta questão, 50\% tem a categoria de master black belts, $86 \%$ tem a categoria de black belts, 75\% tem a categoria de green belts, e apenas $6 \%$ e $11 \%$, respectivamente, adotam as categorias de yellow belts e white belts. A Figura 5 apresenta a distribuição do número de belts por categoria, para as empresas que responderam a esta questão.

É importante observar que a receptividade dos colaboradores envolvidos no programa foi apontada como sendo "alta" para a maioria dos respondentes $(84,2 \%)$; em apenas três empresas a receptividade ao programa Seis Sigma foi considerada "baixa". Além disso, 72,5\% das empresas pretendem ampliar o programa nos próximos anos e apenas uma empresa relatou que pretende reduzir seu escopo.

Analisando-se os principais setores que implantaram projetos Seis Sigma nas empresas pesquisadas, observou-se que as áreas de "manufatura" e "financeira" concentram a maioria dos projetos. No que concerne ao número médio de projetos, observa-se que existe grande amplitude entre as empresas da amostra, sendo que o maior número de projetos por ano (ano base 2005) foi de 200, em uma organização do setor de equipamentos agrícolas; no entanto, a média nestas empresas foi de 14 projetos por ano. A Figura 6 ilustra a evolução do número de projetos por ano, vale observar que 15 empresas não informaram o número de projetos Seis Sigma por ano, e outras 3 só tinham este dado para 2005. Embora o questionário solicitasse uma série de cinco anos do número de projetos, nenhuma empresa preencheu os dados para 2001 e 2002, mostrando que o controle deste indicador é ainda recente.

Observa-se na Figura 6 que o número de projetos por ano tem evoluído paulatinamente, sendo que o número médio para amostra foi de 6, 10 e 14, para os anos de 2003, 2004 e 2005 , respectivamente.

No que concerne ao acompanhamento dos projetos Seis Sigma, verificou-se que a periodicidade é semestral em $28 \%$, seguida da trimestral, $26 \%$. O número de respondentes para esta questão foi de 39 organizações, sendo que alguns relataram na opção outros que, embora não haja uma periodicidade estabelecida, o acompanhamento é feito de forma sistemática pelo champion e em apenas uma empresa foi relatado que existe auditoria dos projetos Seis Sigma. Finalmente, destaca-se que $89 \%$ das empresas adotam algum tipo de premiação, destas, $22 \%$ adota prêmio em espécie.

As principais ferramentas da qualidade adotadas nas empresas da amostra, dentro do contexto do programa Seis Sigma, foram a análise de variância e o diagrama de causaefeito, ambas com $85 \%$ de utilização. Com uma utilização também expressiva destacam-se o FMEA (Análise do Modo e Efeito da Falha), histograma e o teste de hipótese, todos

Figura 5: Distribuição do número de belts por categoria.

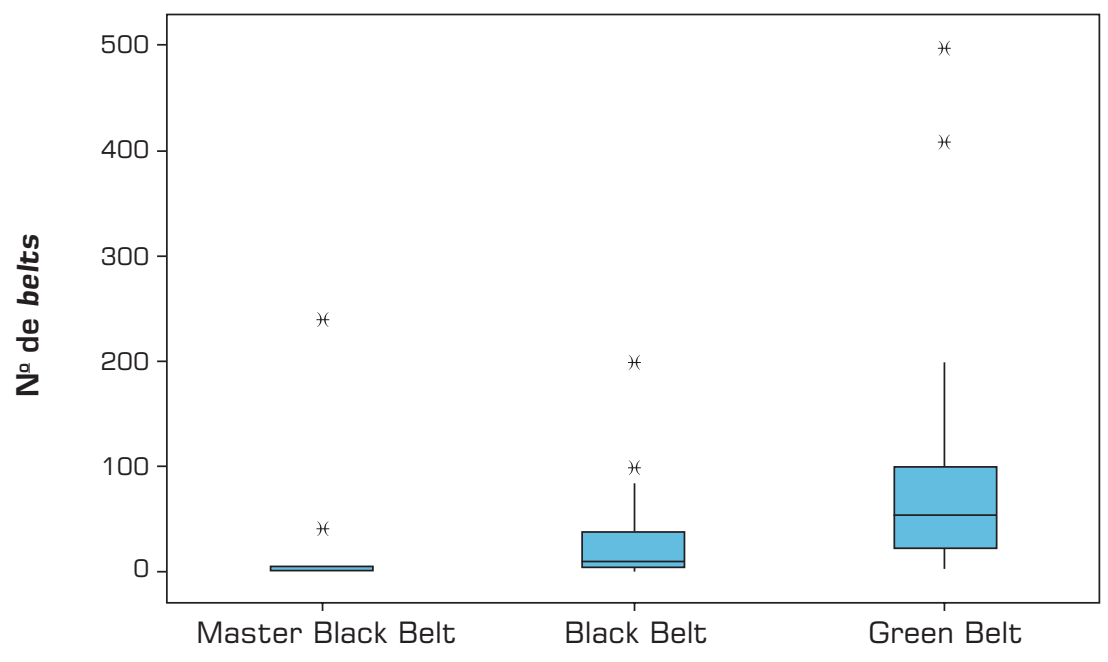


com 78\%. Observa-se que mesmo as ferramentas estatísticas mais complexas, como a análise de variância e o teste de hipótese, são bastante utilizadas (ver Figura 7).
Vale destacar ainda que 38\% das empresas pesquisadas adotam, além do DMAIC, o projeto para Seis Sigma-DFSS (design for six sigma).

Figura 6: Evolução do número de projetos Seis Sigma por ano.

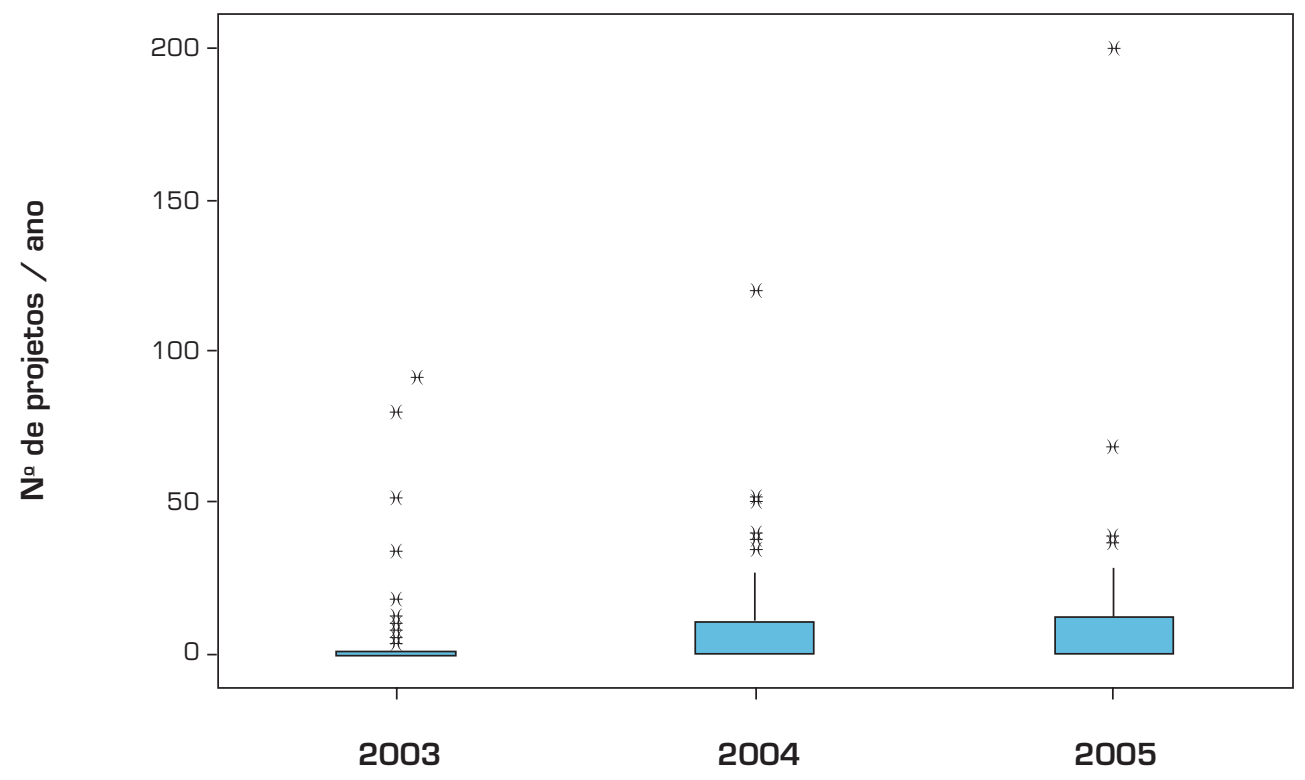

Figura 7: Utilização das ferramentas de qualidade no programa Seis Sigma.

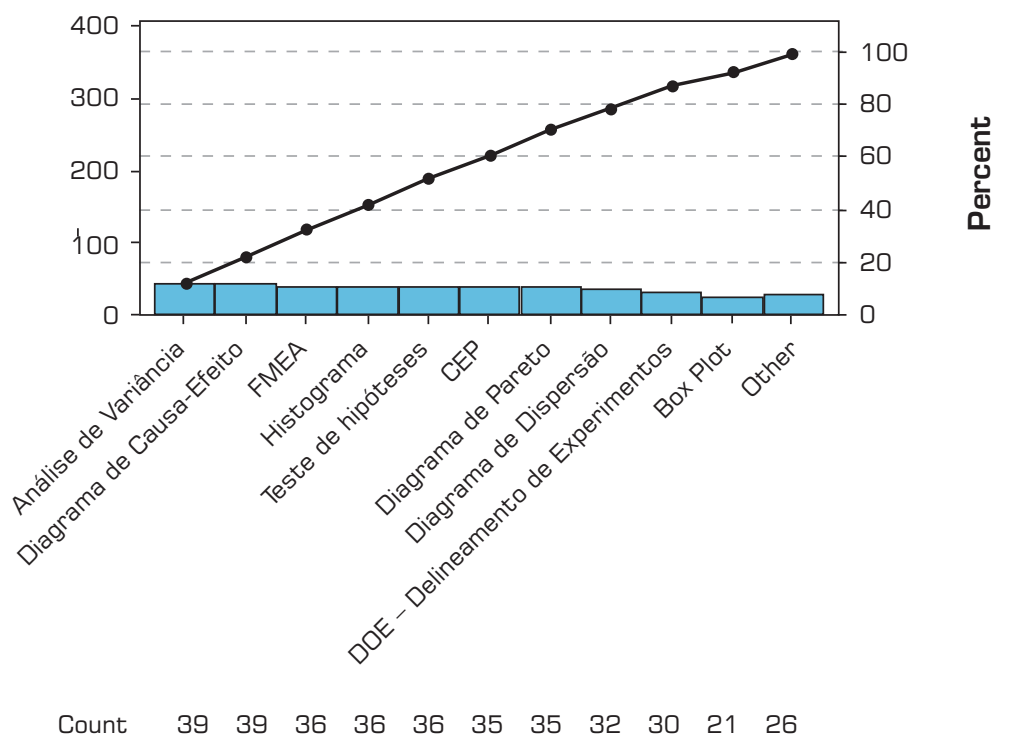




\section{Resultados obtidos com a implementação do Programa Seis Sigma}

Os principais resultados apontados pelas empresas pesquisadas como oriundos do programa Seis Sigma foram "maior qualidade" (85\%) e ganhos financeiros (83\%). Foram também relatados, por 36 empresas $(78 \%)$, uma "maior produtividade" e "maior satisfação dos clientes internos" $(70 \%)$ e externos $(67 \%)$, conforme ilustra a Figura 8.

Nas questões que buscavam quantificar os ganhos obtidos, em face da faixa de investimento aportado no programa, consideraram-se apenas os respondentes que informaram ambos: os valores investidos e os ganhos financeiros para análise destes resultados. O ponto médio de cada faixa de intervalo do ganho obtido foi considerado para o cálculo do ganho médio obtido pelas empresas. Os resultados estão dispostos na Tabela 1. Pode-se observar que não existe uma correlação positiva entre os valores investidos e os ganhos obtidos. Um fato que chama a atenção é: as empresas que investiram entre 50 até 100 mil apresentaram o maior ganho médio, porém o desvio padrão deste grupo de empresas também foi o maior, indicando uma grande variação dos ganhos obtidos neste grupo de empresas.

Análise semelhante foi feita em relação ao Estado de origem, conforme Tabela 2. Menores valores investidos em RS e SC e maiores em MG e SP, assim como o ganho obtido, no entanto em SC o ganho relativo foi muito maior $(36 \%)$.
Não obstante, vale ressaltar que, em sua maioria (73\%), as empresas pesquisadas não fazem a consolidação dos ganhos através de uma área financeira ou uma controladoria, em apenas 8 empresas (18\%) observou-se esta prática. Isto pode explicar a dificuldade em apontar os ganhos obtidos com o programa Seis Sigma.

A apuração dos ganhos dos projetos Seis Sigma, nas 30 empresas da amostra que responderam a esta pergunta, foi feita predominantemente pelo cálculo do Valor Presente Líquido (VPL), em 40\%, seguida da redução do custo direto, calculada em 30\% das empresas. Outros indicadores relatados foram: custo indireto, análise do valor agregado (EVA) e retorno sobre o investimento (ROI).

\section{CONSIDERACÕES FINAIS}

Embora o programa Seis Sigma ainda esteja se difundindo no Brasil, neste estudo foi possível observar que das 198 empresas de grande porte que responderam ao questionário, apenas 46 organizações tinham implementado o programa Seis Sigma $(\sim 23 \%)$. Este valor representa uma porcentagem inferior àquela encontrado por Antony e Banuelas (2004) nas empresas de grande porte do Reino Unido (37\%).

Dentre as 46 empresas da amostra que implementam o programa Seis Sigma, a maioria tem faturamento anual superior a cinqüenta milhões de reais e mais de mil colaboradores e está situada no Estado de São Paulo. Destas

Figura 8: Resultados obtidos com a implementação do programa Seis Sigma.

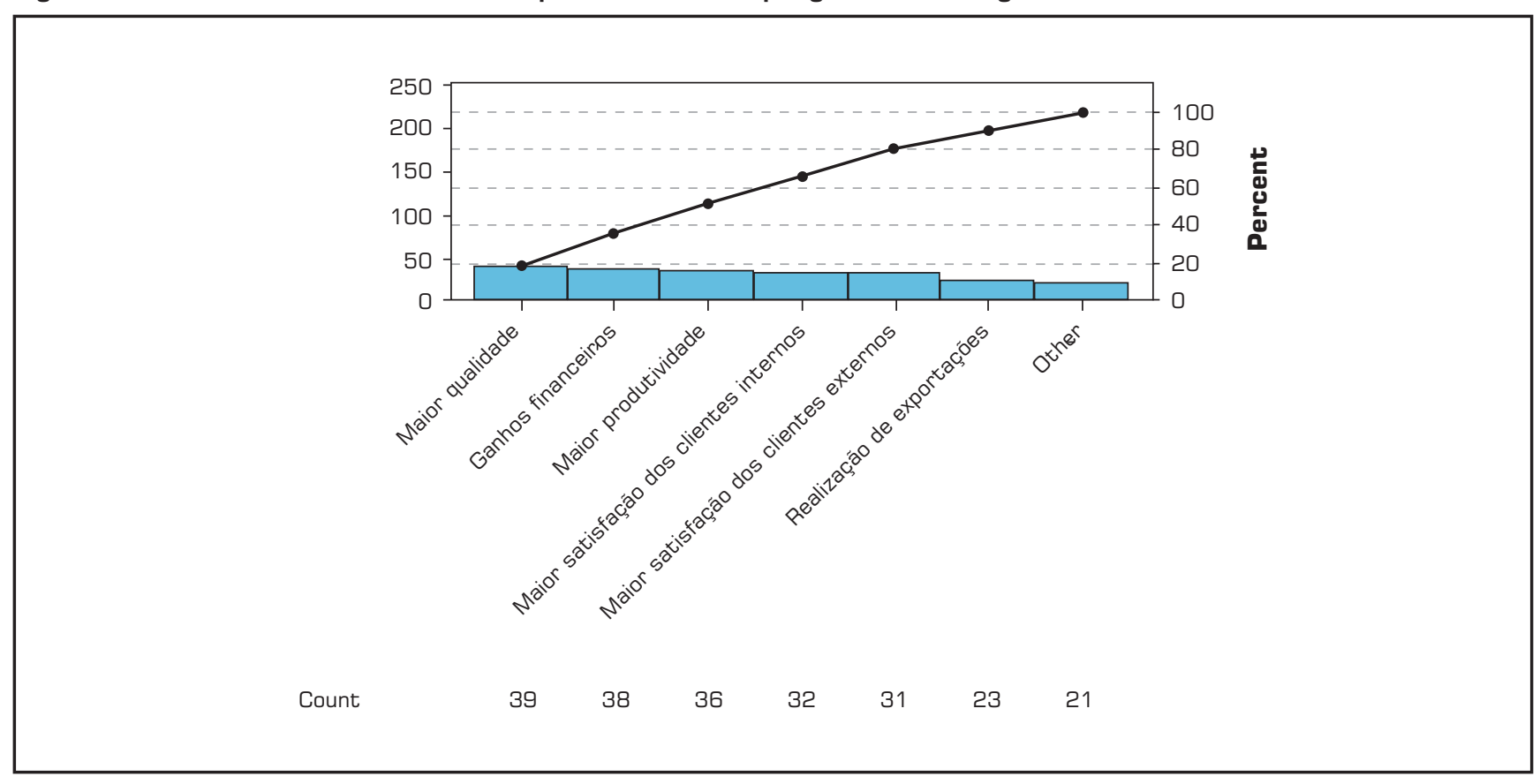


empresas, pode-se verificar que há incidência predominantemente de empresas de manufatura, em especial do setor "metalomecânico" e de "veículos automotores e autopeças", o que também é coerente com os resultados disponíveis na literatura (BLAKESLEE, 2001, ECKES, 2001, PANDE et al., 2001, SNEE; HOERL, 2002, INGLE; ROE, 2001, BOARIN PINTO, 2006).

O programa Seis Sigma nestas empresas já tem um tempo de implementação médio de 6,75 anos, e a motivação predominante foi a busca da melhoria da qualidade e produtividade, o que não confirma o foco no cliente, conforme sugere a literatura (ver o tópico "Programa Seis Sigma:síntese da discussão teórica"). Além disto, observou-se que a adoção do programa Seis Sigma está em geral associada a outras abordagens de gestão da qualidade, em especial a certificação ISO 9001:2000.

Para as empresas pesquisadas, um dos fatores-chave na implementação do programa Seis Sigma é o "envolvimento e o comprometimento da alta administração com o programa", conforme já enfatizava a literatura (ANTONY; BANUELAS, 2002; KWAK; ANBARI, 2004; STARBIRD, 2002, JOHNSON; SWISHER, 2003). No entanto, este fator aparece em segundo lugar, sendo que a "disponibilidade de recursos financeiros" figurou na primeira colocação. As principais dificuldades encontradas na implementação do programa foram a "disponibilidade dos funcionários" e a "complexidade das operações".
Observa-se também que, mesmo as ferramentas estatísticas mais complexas, como a análise de variância (85\%), o teste de hipótese (85\%) e DOE (design of experiment) $(65 \%)$ são expressivamente usadas nos projetos Seis Sigma. Pesquisa realizada por Kruglianskas (1995) apontava para o fato do DOE em especial e técnicas estatísticas de maneira geral serem pouco difundidos entre as empresas.

A análise dos ganhos obtidos na implementação do programa Seis Sigma permitiu observar que não existe uma correlação positiva entre os valores investidos e os ganhos obtidos. Não obstante, vale ressaltar que, em sua maioria (73\%), as empresas pesquisadas não fazem a consolidação dos ganhos através de uma área financeira ou uma controladoria; o que pode explicar a dificuldade em apontar os ganhos obtidos.

Esta pesquisa de campo apresenta as limitações inerentes ao método de pesquisa adotado, com amostra não probabilística e partindo da percepção dos respondentes, o que traz um viés na análise. Não obstante, diversas empresas líderes de vários setores responderam a este estudo, o que permite traçar uma análise de tendência da implementação deste programa em empresas de grande porte. Ainda merece destaque em uma agenda futura de pesquisas um entendimento aprofundado das relações entre investimento e ganho, tanto no contexto específico dos projetos Seis Sigma como do programa como um todo.

Tabela 1: Ganho médio por faixa de investimento no programa Seis Sigma.

\begin{tabular}{|c|c|c|c|}
\hline FAIXA DE VALORES INVESTIDOS & $\begin{array}{l}\text { GANHO MádIO } \\
\text { Rs(X 10 } 10^{3}\end{array}$ & $\begin{array}{l}\text { DESVIO PADRÃO } \\
\left.\text { R\$(X 10 } 10^{3}\right)\end{array}$ & $\begin{array}{c}\text { \# DE } \\
\text { RESPONDENTES }\end{array}$ \\
\hline de $R \$ 10.000$ a $R \$ 49.999$ & 375 & 0 & 1 \\
\hline de $R \$ 50.000$ a $R \$ 99.999$ & 681 & 454 & 5 \\
\hline de $R \$ 100.000$ a $R \$ 249.999$ & 425 & 239 & 7 \\
\hline de $R \$ 250.000$ a $R \$ 499.999$ & 275 & 141 & 2 \\
\hline de $R \$ 500.000$ a $R \$ 1.000 .000$ & 437,5 & 153 & 6 \\
\hline mais de 1.000 .000 & 500 & 217 & 3 \\
\hline
\end{tabular}

Tabela 2: Ganho médio por Estado.

\begin{tabular}{|l|c|c|c|}
\hline ESTADO & $\begin{array}{c}\text { VALOR MÉdIO INVESTIDO } \\
\left.\text { RS(X 10 }{ }^{3}\right)\end{array}$ & $\begin{array}{c}\text { GANHO MÉDIO } \\
\left.\text { RS(X 10 }{ }^{3}\right)\end{array}$ \\
\hline MG & 415 & 432 & 4 \\
\hline RS & 175 & 175 & 0 \\
\hline SC & 275 & 375 & 36 \\
\hline SP & 463,8 & 521,9 & 12,5 \\
\hline RJ e BA & n.inf. & n.inf. & n.inf \\
\hline
\end{tabular}




\section{Artigo recebido em 22/06/2007 \\ Aprovado para publicação em 27/10/2007}

\section{- Referências}

AGUIAR, S. Integração das ferramentas da qualidade ao PDCA e ao programa Seis Sigma. Belo Horizonte: Editora de Desenvolvimento Gerencial, 2002.

ANBARI, F. T. Six Sigma Method and Its Applications in Project Management. Proceedings of the Project Management Institute Annual Seminars and Symposium. Project Management Institute. San Antonio, Texas, Oct, 2002.

ANTONY, J.; BANUELAS, R. Key ingredients for the effective implementation of Six Sigma program. Measuring Business Excellence, v. 6 (4), p. 20-27, 2002.

ANTONY, J. Six Sigma in the UK service organisations: results from a pilot survey. Managerial Auditing Journal, v. 19, n. 8, p. 1006-1013, 2004.

ARNHEITER, D.A.; MALEYEFF, J. The integration of lean management and Six Sigma. The TQM Magazine, v. 17 (1), p. 5-18, 2005.

BABBIE, E. Métodos de pesquisa de survey. Belo Horizonte: Editora UFMG, 1999.

BASU, R. Six-Sigma to operational excellence: role of tools and techniques. International Journal of Six Sigma and Competitive Advantage, v. 1 (1), p. 4464, 2004.

BLAKESLEE JR, J. A. Achieving quantum leaps in quality and competitiveness: implementing the Six Sigma solution in your company. ASQ'S 53RD ANNUAL QUALITY CONGRESS PROCEEDINGS. USA, 2001. Anais. p. 486-496.

BOARIN PINTO, S. H.; CARVALHO, M. M.; LINDA, L. H. Implementação de programas de qualidade: um survey em empresas de grande porte no Brasil. Gestão \& Produção, v. 13 (2), p. 191-203, 2006.

BREYFOGLE, F. W. Implementing Six Sigma, smarter solutions - Using Statistical Methods, New York: Wiley, 1999.

BRYMAN, A. Research methods and organization studies. London: Routledge, 1989.
CAMPANELLA, J. Principles of Quality Costs: principles, implementation and use. 3. ed. Milwaukee: ASQ Quality Press, 1999

CARVALHO, M. M.; ROTONDARO, R. G. Gestão da qualidade em serviços. In CARVALHO, M. M..; PALADINI, E.P. (Org.). Gestão da Qualidade: Teoria e Casos. Rio de Janeiro: Campus, p. 331-351, 2006.

CARVALHO, M. M. Selecionado Projetos Seis Sigma. ROTONDARO, R. G. (Org.) Seis Sigma estratégia gerencial para a melhoria dos processos, produtos e serviços. São Paulo: Atlas, p.49-79, 2002.

CONNOR, G. Benefiting from Six Sigma. Manufacturing Engineering, v. 130 (2), p. 53-59, Feb. 2003.

COOPER, N. P.; NOORNAN, P. Do teams and Six Sigma go together. Quality Progress, p. 25-28, June, 2003.

COOPER, R. D., SCHINDLER, P. S. Método de pesquisa em administração. 7. ed. Porto Alegre: Bookman: 2003.

DALE, B. G., WILLIAMS, R. T.; WIELE, T Marginalisation of quality: is there a case to answer? The TQM Magazine, v. 12 (4), p. 266-274, 2000.

DEFEO, J. A. Six Sigma: New opportunities for HR, new career growth for employees. Employment Relations Today, v. $27(2)$, p. 1-6, 2000

De MAST, J. A methodological comparison of three strategies for quality improvement. The International Journal of Quality \& Reliability Management, v. 21, n. 2, p.198-213, 2004

ECKES, G. The Six Sigma revolution: How General Electric and others turned process into profits. New York: John Wiley \& Sons, 2001

ELLIOTT, George. The race to Six Sigma. Industrial Engineer, p. 30-35, Oct. 2003.

GODOY, A. S. Pesquisa qualitativa: tipos fundamentais. RAE - Revista de Administração de Empresas, São Paulo, v. 35, n. 3, p. 20-29, 1995
HAIR JR., J. F.; TATHAM, R. L.; ANDERSON, R. E.; BLACK, W. Análise multivariada de dados. 5. ed. Porto Alegre: Bookman, 2005.

HAMMER, M. Process management and the of Six Sigma. MIT Sloan Management Review, p. 26-33, Winter 2002.

HARRY, M. J. Six Sigma: a breakthrough strategy for profitability. Quality Progress, p. 60-65, Mai 1998.

HARRY, M.; SCHROEDER, R. Six Sigma: the breakthrough management strategy revolutionizing the world 's top corporations. Nova York: Currency, 2000.

HEUVEL, J. D.; DOES, R. J. M. M.; VERVER, J. P. S. Six Sigma in healthcare: lessons learned from a hospital. International Journal of Six Sigma and Competitive Advantage. n. 4(1), p. 380-388, 2005.

HOERL, R. Six Sigma black belts: what do they need to know. Journal of Quality Technology, v. 33 (4), 2001.

HOERL, R.; SNEE, R. D. Statistical thinking: improving business performance. Pacific Grove, CA: Duxbury Press, 2002.

INGLE, S.; ROE, W. Six Sigma. Black Belt Implementation, v. 13 (4), p. 273-280, 2001.

JOHNSON, A., SWISHER, B. How six sigma improves R\&D, Research Technology Management, March-April, p. 12-15, 2003.

JURAN, J. M. Quality Control Handbook. McGraw-Hill, 2. ed., 1962.

KWAK, Y.; ANBARI, F. Benefits, obstacles, and future of six sigma approach. Technovation, xx, p. 1-8, 2004.

KRUGLIANSKAS, I. Engenharia simultânea e técnicas associadas em empresas tecnologicamente dinâmicas. Revista de Administração, v. 30, n. 2, p. 25-38, 1995.
LLORÉNS-MONTES, J. F.; MOLINA, L. M. Six Sigma and management theory: processes, content and effectiveness. Total Quality Management, n. 4 (17), p. 485-506, 2006

LINDERMAN, K.; SCHROEDER, R.G.; ZAHEER, S.; CHOO, A. Six Sigma: a goaltheoretic perspective. Journal Operations Management, p. 193-203, 2003.

LYNCH, D. P.; BERTOLINO, S.; CLOUTIER, E. How to scope DMAIC projects. Quality Progress, p. 37-42, Jan. 2003

MCADAM, R.; EVANS, A. The organizational contextual factors affecting the implementation of Six Sigma in a high technology mass-manufacturing environment. International Journal of Six Sigma and Competitive Advantage, v. 1 (1), p. 29-43, 2004.

MCADAM, R.; LAFFERTY, B. A multilevel case study critique of six sigma: statistical control or strategic change? International Journal of Operations \& Production Management, v. 24 (5), p. 530-49, 2004.

MITCHELL, B. The Six Sigma appeal. Engineering Management Journal, p. 4147, Feb. 1992.

OLEXA, R. Flying high with Six Sigma. Manufacturing Engineering, v. 130 (2), p. 69-73, Feb. 2003.

PANDE, P S.; NEUMAN, R. P.; CAVANAGH, R. R. Estratégia Seis Sigma. Como a GE, a Motorola e outras grandes empresas estão aguçando seu desempenho. Rio de Janeiro: Qualitymark, 2001.

PFEIFER, T., REISSIGER, W., CANALES C. Integrating six sigma with quality management systems. The TQM Magazine, v. 16 (4), p. 241-249, 2004 


\section{- Referências}

PHILLIPS, E. J. Six Sigma: the breakthrough management strategy revolutionizing the world's top corporations. Consulting Management, v. 13 (4), p. 57-59, Dec. 2002 .

RICONDO, I., VILES, E. Six Sigma and it links to TQM, Re-engineering, Lean and Learning Organization. In: FIRST INTERNATIONAL CONFERENCE ON SIX SIGMA, 1., Glasgow, 2004. Anais. Glasgow, 2004. p. 29-43.

ROBERTS, C. M. Six Sigma signals. Credit Union Magazine, p. 40-45, Jan. 2004.

ROTONDARO, R. G. Visão Geral ROTONDARO, R. G. (Org.) Seis Sigma estratégia gerencial para a melhoria dos processos, produtos e serviços. São Paulo Atlas, 2002, p. 17-22.
SEHWAIL, L.; DE YONG, C. Six sigma in health care. International Journal of Healthcare Quality Assurance, v. 16 (4), p. 1-5, 2003.

SENAPATI, N. R. Six Sigma: myths and realities. International Journal of Quality \& Realibility Management, v. 21, n. 6, p. 683-690, 2004.

SHANKAR, N. K. ISO 9000: integration Europe and North America. European Quality, p. 20-29, Sept. 2003.

SNEE, R. D.; HOERL, R. W. A Step-by-Step Guide Based on Experience with GE and Other Six Sigma Companies. Financial Times. Prentice Hall, 2002.
SNEE, R. D. Six-Sigma: the evolution of 100 years of business improvement methodology. International Journal of Six Sigma and Competitive Advantage, v. 1 (1), p. 4-20, 2004.

STARBIRD, D. Business Excellence: Six Sigma as a management system. ASQ's 56th ANNUAL QUALITY CONGRESS PROCEEDINGS. Anais, p. 47-55, 2002.

SUN, H.; LI, S.; HO, K.; GESTERN, F.; HANSEN, P.; FRICK, J. The trajectory of implementing ISO 9000 standards versus total quality management in Western Europe. International Journal of Quality \& Reliability Management, v. 21 (2), p. 131-153, 2004
VALOR 1000. As 1000 maiores empresas e as campeãs por setor e região. Jorna Valor Econômico, Jul. 2004

WATSON, J. J. Satisfaction through Six Sigma. Engineered Systems, p. 94-98, Mar. 2003

WELCH, J. Jack Welch por Jack Welch. HSM Management, p.18-30, Nov./Dec. 2003a.

WELCH, J. Os difusores: GE e Jack Welch. HSM Management, p. 86-90, May/June 2003b.

WOLEK, F. W. The lesson of guild history: variance reduction must be balanced with innovation. The Quality Management Journal, v. 11 (2), p. 33-40, 2004.

\section{Agradecimentos}

Os autores agradecem ao CNPq e à FAPESP pelo financiamento parcial desta pesquisa.

\section{- Sobre os autores}

\section{Marly Monteiro de Carvalho}

Prof.a. Livre-docente do Depto. de Eng. Produção - Escola Politécnica da USP

End.: Av. Prof. Almeida Prado, 128 Tr.2 Biênio 2o andar - 05508-900 São Paulo - SP - Brasil

Tel.: (11) 3091-5363 Fax: (11) 3091-5399 r. 303

E-mailmarlymc@usp.br

\section{Linda Lee Ho}

Prof.a. Livre-docente do Depto. de Eng. Produção - Escola Politécnica da USP

End.: Av. Prof. Almeida Prado, 128 Tr.2 Biênio 2o andar - 05508-900 - São Paulo - SP - Brasil

Tel.: (11) 3091-5363 Fax: (11) 3091-5399 r. 404

E-mail lindalee@usp.br

\section{Silvia Helena Boarin Pinto}

Pós-doutoranda do Depto. de Eng. Produção - Escola Politécnica da USP

End.: Av. Prof. Almeida Prado, 128 Tr.2 Biênio 2o andar - 05508-900 - São Paulo - SP - Brasil

Tel.: (11) 3091-5363 Fax: (11) 3091-5399 r. 400

E-mailshboarin@uol.com.br 